\title{
Facile and Manifest Liquid Chromatographic Method for the Simultaneous Determination of Enalpril Maleate and NSAIDs in API and Pharmaceutical Formulations
}

\author{
Najma Sultana ${ }^{1}$, Safila Naveed ${ }^{2,3 *}$ and M Saeed Arayne ${ }^{1}$ \\ ${ }^{1}$ Research Institute of Pharmaceutical Sciences Faculty of Pharmacy, University of Karachi, Karachi, Pakistan \\ 2Jinnah University for Women, Karachi, Pakistan \\ ${ }^{3}$ Department of Chemistry, University of Karachi, Karachi, Pakistan
}

\begin{abstract}
Patients diagnosed with hypertension are prescribed an large number of medications for appropriate therapy, increasing risk of side effects or drug interactions. Enalapril, ACE inhibitor is commonly used as a drug of choice for the treatment of hypertension. On the other hand, NSAIDs are generally used for the treatment of pain, fever and inflammation, particularly in arthritis. A simple, efficient, economical and least time consuming isocratic method for the simultaneous determination of enalapril (ENP) and non-steroidal anti-inflammatory drugs (flurbiprofen, diclofenac sodium, ibuprofen and mefanamic) in bulk, pharmaceutical formulations and human serum using high performance liquid chromatography (HPLC) has been developed and validated. ENP was separated from NSAIDs using a Purospher STAR C18 column $(250 \times 4.6 \mathrm{~mm}, 5 \mu \mathrm{m})$ and a mobile phase consisting of methanol, water $(80: 20$, $\mathrm{v} / \mathrm{v}, \mathrm{pH}$ was adjusted by ortho phosphoric acid to 2.8 at a flow rate of $1.8 \mathrm{~mL} \mathrm{~min}^{-1}$ and at ambient temperature. Effluents from the column were monitored at $225 \mathrm{~nm}$. The retention time of ENP was 4.1 minute and that for flurbiprofen, diclofenac sodium, ibuprofen and mefanamic acid was 5.4, 5.9, 6.4 and 8.7 mins respectively. LLOD and LLOQ of enalapril were 0.7 and $2.2 \mathrm{ng} \mathrm{ml}^{-1}$ respectively and that of flurbiprofen, diclofenac sodium, ibuprofen and mefanamic were $0.24,0.07,0.1,0.1$ and $0.7,0.2,0.3$ and $0.4 \mathrm{ng} \mathrm{ml}^{-1}$ respectively. The method was validated according to $\mathrm{ICH}$ guidelines. Linearity of the method was studied in the concentration range $2.5-100 \mu \mathrm{g} \mathrm{mL}^{-1}$ for ENP and $0.625-25 \mu \mathrm{g} \mathrm{mL}^{-1}$ for (NSAIDs) where it demonstrated good linearity with $\mathrm{r}=0.9995,0.9979,0.9995,0.9967$ 0.9967 and $0.9995(n=6)$, respectively, recovery was $>97.8 \%$. The developed method may successfully be applied for the quantitative analysis of ENP and NSAIDs alone or in combination from raw materials, in bulk drugs, dosage formulations and in serum.
\end{abstract}

Keywords: Enalpril maleate; Flurbiprofen; Diclofenac sodium; Ibuprofen, Mefenamic acid, RP-HPLC

\section{Introduction}

Enalapril maleate is chemically described as (S)-1-[N-[1(ethoxycarbonyl) -3-phenylpropyl]-L-alanyl] -L-proline, (Z)-2butenedioate salt (Figure 1) [1]. It is an ester prodrug which is hydrolyzed to pharmacologically active enalaprilate, a specific competitive inhibitor of ACE, It inhibits the active sites of a zinc glycoprotein, the angiotensin converting enzyme (ACE) blocking the conversion of angiotensin I to angiotensin II, whose levels are elevated in patients with hypertension [2].

Hypertension and musculoskeletal are two common coexisting problems for which antihypertensive and analgesics as nonsteroidal anti-inflammatory drugs (NSAIDs) are most commonly prescribed together [3]. Over the last two decades, concern about probable drug interactions between NSAIDs and antihypertensive agents has been grown. Cases with hypertensive emergency have been reported after taking NSAIDs in patients with previously well-controlled hypertension [4,5]. Various HPLC methods have been reported for estimation of enalapril maleate [6-7]. Several methods have also been reported for determination of NSAIDs [8-10].

Our research group has developed and validated simultaneous methods for the co-adminstered drugs as rosuvastatin with NSAIDs [11] and with alprazolam and diclofenac [12]. Lisinopril, captopril $[13,14]$ and metformin $[15]$ have also been simultaneously determined with NSAIDs. Sultana and Arayne et al., have also developed methods for the simultaneous determination of various co-administered drugs as calcium channel blockers with NSAIDS [16,17] and many other drugs [18-23] in raw materials, pharmaceutical formulations

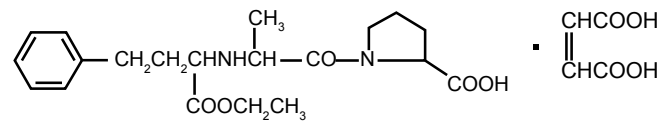

Enalapril<smiles>[R]C([R])C(=O)O</smiles>

\section{Where \\ $\mathrm{R}=\mathrm{H}, \mathrm{CH} 3$ or alkyl $A R=$ aryl or Heteroaryl}

\section{aryl alkanoic acid}

Figure 1: Aryl alkanoic acid.

*Corresponding author: Safila Naveed, Jinnah University for Women, Karachi, Pakistan, E-mail: safila117@yahoo.com

Received May 06, 2013; Accepted May 25, 2013; Published May 27, 2013

Citation: Sultana N, Naveed S, Arayne MS (2013) Facile and Manifest Liquid Chromatographic Method for the Simultaneous Determination of Enalpril Maleate and NSAIDs in API and Pharmaceutical Formulations. Pharm Anal Acta S2: 004. doi:10.4172/2153-2435.S2-004

Copyright: $\odot 2013$ Sultana N, et al. This is an open-access article distributed under the terms of the Creative Commons Attribution License, which permits unrestricted use, distribution, and reproduction in any medium, provided the original author and source are credited. 
and serum. All these developed and validated methods follow ICH guidelines [23] are economical, short time consuming and could be applied to quantitate drugs upto nano gram levels and thus find applications not only in pharma industry but also in clinical and forensic laboratories as well as for pharmacokinetic studies. So keeping in mind the above facts and as no RP-HPLC method is reported for simultaneous estimation of enalapril and NSAIDs we made an attempt to develop and validate a simple economical and time effective method for the simultaneous quantification of enalapril and four NSAIDs in raw material, pharmaceutical formulations and serum. As the LLOD is quite low and the drug could be detected in nano amounts in serum this method is applicable for clinical and forensic laboratories.

\section{Materials and Methods}

\section{Chemicals and reagents}

HPLC grade methanol and phosphoric acid were obtained from Merck, Germany. Enalapril was a gift from Brooks Pharmaceutical Laboratories Pakistan. The NSAIDs used were diclofenac sodium from Yung Shin Pharmaceutical Ind. Co. Ltd, flurbiprofen and ibuprofen, Abbott Laboratories (Pakistan) Ltd and mefenamic acid from Parke Davis and Co. Ltd. Dosage forms of diclofenac sodium (Voren 50 $\mathrm{mg}$ ), flurbiprofen (NSAID 100mg), ibuprofen (Brufen $200 \mathrm{mg}$ ) and mefenamic acid (Ponstan $250 \mathrm{mg}$ ) were purchased from the local pharmacy. All these drugs had an expiry of not less than one year at the time of study.

\section{Instrumentation}

Two identical LC systems of two different labs were used for the separation in order to ensure ruggedness of the method. Shimadzu HPLC system consisted of LC-10 AT VP pump, DGU-14 AM on-line degasser, rheodyne manual injector fitted with a $20 \mu \mathrm{L}$ loop, and SPD10 A VP UV-VIS detector and a Purospher star C18 (5 $\mu \mathrm{m}, 25 \times 0.46$ $\mathrm{cm})$ column was utilized for separation. Chromatographic system was integrated via Shimadzu model CBM-102 Communication Bus Module to P-IV computer loaded with CLASS-GC software (Version 5.03) for data acquisition and mathematical calculations.

\section{Chromatographic conditions}

The mobile phase containing methanol: water (80:20), $\mathrm{pH}$ was adjusted to $\mathrm{pH} 2.5$ with orthophosphoric and filtered through 0.45 micron membrane filter and then ultrasonicated for 10 mins. The flow rate was set to $1.0 \mathrm{ml} \mathrm{min}^{-1}$.

\section{Preparation of stock solutions}

Stock solutions of $100 \mu \mathrm{g} \mathrm{mL} \mathrm{L}^{-1}$ of enalapril, ibuprofen, flurbiprofen, diclofenac sodium and mefenamic acid were prepared individually by dissolving $10 \mathrm{mg}$ of each drug in $100 \mathrm{~mL}$ volumetric flask using mobile phase as a diluent. Aliquots were diluted in the range of $0.625-$ $25 \mu \mathrm{g} \mathrm{mL}^{-1}$ for ibuprofen, diclofenac sodium, mefenamic acid and flurbiprofen and for enalapril 2.5-100 $\mu \mathrm{g} \mathrm{mL}^{-1}$ for. These solutions were stored at $20^{\circ} \mathrm{C}$, they were prepared once and analyzed daily for inter-day and inter-operator variations of the method, $20 \mu \mathrm{L}$ of these solutions were injected into LC system and chromatographed.

\section{Calibration curve}

Calibration curves were prepared by taking appropriate aliquots of standard EM and NSAIDs stock solutions in different $10 \mathrm{ml}$ volumetric flask and diluted up to the mark with mobile phase to obtain final concentrations of $2.5,5,10,25,50,100 \mu \mathrm{g} \mathrm{ml}^{-1}$ of EM and 0.625, 1.25, $2.5,6.25,12.5$ and $25 \mu \mathrm{g} \mathrm{ml}^{-1}$ of NSAIDs. Standard solutions $(\mathrm{n}=6)$ were injected through $20 \mu \mathrm{l}$ loop system and chromatograms were obtained using $1.0 \mathrm{ml} \mathrm{min}{ }^{-1}$ flow rate. The effluent was monitored at $225 \mathrm{~nm}$. Calibration curve was constructed by plotting average peak area against concentration and regression equation was computed, chromatogram is depicted in figure 2 .

\section{Validation of the method}

The developed method was validated in terms of linearity, accuracy, specificity, limit of detection, limit of quantification, intra-day and inter-day precision and repeatability of measurement.

\section{Sample preparation}

To determine the content of the drugs in pharmaceutical formulations, 20 tablets of each formulation were powdered and an amount equivalent to $10 \mathrm{mg}$ of EM and $2.5 \mathrm{mg}$ of NSAIDs was transferred to $100 \mathrm{~mL}$ volumetric flask, $50 \mathrm{ml}$ of mobile phase was added and the flask was kept in an ultrasonic bath for 10 mins. The resulting solutions were filtered through a $0.45 \mu \mathrm{m}$ filter paper and diluted to the desired concentration and analyzed for the drug content, chromatogram is depicted in figure 3.

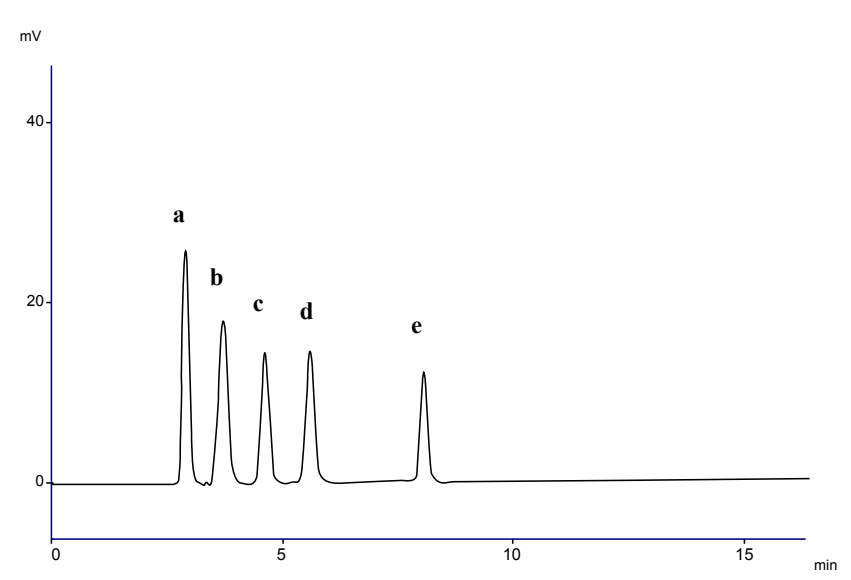

Figure 2: A representative chromatogram of (a) enalapril (b) flurbiprofen (c) diclofenac sodium (d) ibuprofen and (e) mefanimic acid in raw material.

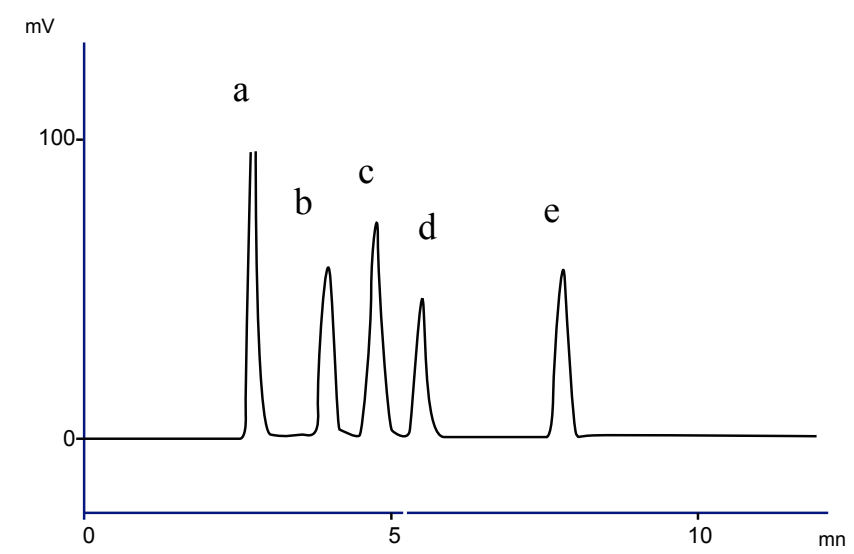

Figure 3: A representative chromatogram of (a) enalapril (b) flurbiprofen (c) diclofenac sodium (d) ibuprofen and (e) mefanamic acid in formulation. 


\section{Results and Discussion}

This work was designed to develop an isocratic method based on RP-HPLC separation combined with UV detection for ENP and NSAIDs assay in API and pharmaceuticals dosage formulations. The goal of this study was to develop a rapid, more accurate, precise, reliable, least time consuming HPLC method for the drugs individually as well as simultaneously. This analytical method was developed taking in account the therapeutic concentrations range and overdose concentrations range, has been validated and holds well for the determination of drug in raw materials and dosage formulations.

Our research group has been involved in the developments of new and efficient RP-HPLC methods for the determination of drugs alone as well as simultaneous determination of co-adminstered drugs. As in these methods the drug could be quantitated upto nanogram levels so they can also be applied for clinical laboratories, serums as well as forensic medicines.

To develop a precise, accurate and suitable RP- HPLC method for the simultaneous estimation of EM and NSAIDs, different mobile phases ratios $(50: 50,60: 40,70: 30,80: 20 \mathrm{v} / \mathrm{v})$ of methanol: water were tried and the best selected mobile phase was 80:20 methanol: water. The $\mathrm{pH}$ of the mobile phase was adjusted with orthophosphoric acid and tried in the range 2 to 3 where the best tailing results were obtained with $\mathrm{pH}$ 2.8. The proposed chromatographic conditions were found to be appropriate for the quantitative determination. The short analysis time $(<10 \mathrm{~min})$ also enables its application in routine and qualitycontrol analysis of finished products.

\section{Method validation}

The proposed HPLC method was validated as per ICH guidelines [21]. Where specificity, linearity, accuracy, precision, robustness and ruggedness were studied which were well in accordance to $\mathrm{ICH}$ guidelines.

Specificity: The peak purity of EM and NSAIDs was assessed by comparing the retention time (RT) of standard EM and NSAIDs. Good correlation was obtained between the retention time of standard and sample of EM and NSAIDs.

Linearity: Linearity was studied by preparing standard solutions at different concentration levels. The linearity range for EM and NSAIDs was found to be $2.5-100 \mu \mathrm{g} \mathrm{ml}^{-1}$ and $0.625-25 \mu \mathrm{g} \mathrm{ml}^{-1}$, respectively. The regression equation for EM and NSAIDs is given in table 1.

Accuracy (Recovery studies): To check the degree of accuracy of the method, recovery studies were performed in triplicate by standard addition method at $80 \%, 100 \%$ and $120 \%$. Known amounts of standard EM and NSAIDs were added to pre-analyzed samples and were subjected to the proposed HPLC method. Results of recovery studies are shown in table 2 .

Precision: Precision was evaluated by carrying out six independent sample preparations of a single lot of formulation. The sample solution was prepared in the same manner as described in sample preparation. Percentage relative standard deviation (\%RSD) was found to be less than $2 \%$ for within a day and day to day variations, which proves that method is precise. Results are shown in table 3.

Sensitivity: The lower limit of quantitation (LLOQ) of the method as signal/noise of enalapril, diclofenac acid, mefenamic acid, flurbiprofen and ibuprofen was found to be $2.2,0.7,0.2,0.3$ and 0.4 ng $\mathrm{mL}^{-1}$ respectively. Similarly a signal/noise of 3, a LOD of enalapril, diclofenac acid, mefenamic acid,flurbiprofen and ibuprofen was determined to be $0.7,0.24,0.07,0.1$ and $0.1 \mathrm{ng} \mathrm{mL}^{-1}$, respectively.

Ruggedness: Ruggedness of this method was evaluated in two different labs with two different instruments. Lab 1 was in the Research Institute of Pharmaceutical Sciences, Faculty of Pharmacy University of Karachi, while Lab 2 was in the Department of Chemistry, Faculty of Science, University of Karachi. The method did not show any notable deviations in results from acceptable limits.

Robustness of method: To evaluate the robustness of the developed RP-HPLC method, small deliberate variations in the optimized method parameters were done. The effect of change in flow rate, $\mathrm{pH}$ and mobile phase ratio on the retention time and tailing factor were studied. The method was found to be unaffected by small changes like \pm 0.1 change in $\mathrm{pH}, \pm 0.1$ change in flow rate and \pm 1 change in mobile phase (Table $4)$.

\section{Conclusion}

The proposed RP-HPLC method allows for accurate, precise and reliable measurement of EM and NSAIDs simultaneously in combined dosage form within a short time. The developed RP-HPLC method was found to be simple, rapid, selective, accurate, precise and economical for the concurrent estimation of drugs in multiple drugs therapy of EM and NSAIDs. The RSD for all parameters was found to be less than one, which indicates the validity of method and assay results obtained by this method are in fair agreement. The developed method can be used for routine quantitative simultaneous estimation of EM and NSAIDs in multicomponent pharmaceutical preparation as well as in clinical laboratories.

\begin{tabular}{|c|c|c|c|c|c|}
\hline Drugs & $\mathbf{r}^{2}$ & & $\begin{array}{l}\operatorname{LLOQ}^{* *} \\
\left.\text { (ngmL }^{-1}\right)\end{array}$ & $\begin{array}{l}\text { Regression } \\
\text { equation }\end{array}$ & $\begin{array}{l}\text { Conc. } \\
\left(\mu \mathrm{gmL}^{-1}\right)\end{array}$ \\
\hline Enalapril & 0.9995 & 0.7 & 2.2 & $A=2340.4 x+3022.3$ & $2.5-100$ \\
\hline $\begin{array}{l}\text { Diclofenac } \\
\text { sodium }\end{array}$ & 0.9995 & 0.24 & 0.7 & $A=9368.9 x+5785.8$ & $0.625-25$ \\
\hline $\begin{array}{l}\text { Mefanimic } \\
\text { acid }\end{array}$ & 0.9967 & 0.07 & 0.2 & $A=18339 x+10493$ & $0.625-25$ \\
\hline Flurbiprofen & 0.9967 & 0.1 & 0.3 & $A=12964 x+4896.7$ & $0.625-25$ \\
\hline Ibuprofen & 0.9995 & 0.1 & 0.4 & $A=9171.4 x+4741$ & $0.625-25$ \\
\hline
\end{tabular}

*Lower limit of detection, **Lower limit of quantification

Table 1: Regression statistics LLOD and LLOQ.

\begin{tabular}{|c|c|c|c|}
\hline Drugs & Conc & \%RSD & \% Recovery \\
\hline \multirow{3}{*}{ Enalapril } & $80 \%$ & 0.01 & 99.96 \\
\cline { 2 - 4 } & $100 \%$ & 0.00 & 100.00 \\
\hline \multirow{3}{*}{ Diclofenac sodium } & $120 \%$ & 0.00 & 99.98 \\
\cline { 2 - 4 } & $80 \%$ & 0.01 & 99.94 \\
\hline \multirow{3}{*}{ Mefanamic acid } & $100 \%$ & 0.00 & 100.09 \\
\cline { 2 - 4 } & $120 \%$ & 0.00 & 100.00 \\
\hline \multirow{3}{*}{ Flurbiprofen } & $80 \%$ & 0.00 & 100.03 \\
\hline \multirow{3}{*}{ Ibuprofen } & $100 \%$ & 0.00 & 100.00 \\
\hline & $120 \%$ & 0.00 & 100.00 \\
\hline & $100 \%$ & 0.01 & 99.89 \\
\hline & $120 \%$ & 0.00 & 99.97 \\
\hline & $100 \%$ & 0.00 & 99.95 \\
\hline & $120 \%$ & 0.01 & 99.85 \\
\hline
\end{tabular}

Table 2: Accuracy in formulations. 
Citation: Sultana N, Naveed S, Arayne MS (2013) Facile and Manifest Liquid Chromatographic Method for the Simultaneous Determination of Enalpril Maleate and NSAIDs in API and Pharmaceutical Formulations. Pharm Anal Acta S2: 004. doi:10.4172/2153-2435.S2-004

Page 4 of 5

\begin{tabular}{|c|c|c|c|c|c|}
\hline \multirow{2}{*}{ Drugs } & \multirow{2}{*}{$\begin{array}{c}\text { Conc. injected } \\
\mu \mathrm{g} \mathrm{mL^{-1 }}\end{array}$} & \multicolumn{2}{|c|}{ Inter-day } & \multicolumn{2}{|c|}{ Intra-day } \\
\hline & & $\%$ RSD & \%Recovery & $\%$ RSD & \%Recovery \\
\hline \multirow{6}{*}{ Enalapril } & 2.5 & 0.0073 & 99.93 & 0.08 & 99.9 \\
\hline & 5 & 0.0078 & 100.02 & 0.09 & 100.0 \\
\hline & 10 & 0.0019 & 100.06 & 0.07 & 100.1 \\
\hline & 25 & 0.001 & 100.17 & 0.062 & 100.2 \\
\hline & 50 & 0.0005 & 99.99 & 0.059 & 100.0 \\
\hline & 100 & 0.0002 & 100.10 & 0.089 & 1001.7 \\
\hline \multirow{6}{*}{$\begin{array}{l}\text { Diclofenac } \\
\text { sodium }\end{array}$} & 0.625 & 0.0121 & 99.88 & 0.095 & 99.9 \\
\hline & 1.25 & 0.0067 & 99.94 & 0.64 & 99.9 \\
\hline & 2.5 & 0.0017 & 99.99 & 0.098 & 100.0 \\
\hline & 6.25 & 0.0008 & 99.99 & 0.12 & 100.0 \\
\hline & 12.5 & 0.0004 & 99.99 & 0.89 & 100.0 \\
\hline & 25 & 0.0002 & 100.00 & 0.032 & 100.0 \\
\hline \multirow{6}{*}{ Mefanamic acid } & 0.625 & 0.004 & 101.12 & 0.48 & 101.1 \\
\hline & 1.25 & 0.0039 & 100.03 & 0.098 & 100.0 \\
\hline & 2.5 & 0.001 & 100.01 & 0.089 & 100.0 \\
\hline & 6.25 & 0 & 99.91 & 0.5 & 99.9 \\
\hline & 12.5 & 0.0002 & 100.01 & 0.045 & 100.0 \\
\hline & 25 & 0 & 100.00 & 0 & 100.0 \\
\hline \multirow{6}{*}{ Flurbiprofen } & 0.625 & 0.0077 & 99.87 & 0.09 & 99.9 \\
\hline & 1.25 & 0.0106 & 99.86 & 0.01 & 99.9 \\
\hline & 2.5 & 0.0014 & 99.97 & 0.089 & 100.0 \\
\hline & 6.25 & 0.0012 & 99.99 & 0.089 & 100.0 \\
\hline & 12.5 & 0.0004 & 99.97 & 0.58 & 100.0 \\
\hline & 25 & 0.0004 & 100.00 & 0.99 & 100.0 \\
\hline \multirow{6}{*}{ Ibuprofen } & 0.625 & 0.0133 & 99.72 & 0.98 & 99.7 \\
\hline & 1.25 & 0.0069 & 99.86 & 0.00689 & 99.9 \\
\hline & 2.5 & 0.002 & 100.03 & 0.08 & 100.0 \\
\hline & 6.25 & 0.001 & 99.93 & 0.9 & 99.9 \\
\hline & 12.5 & 0.0005 & 100.02 & 0.089 & 100.0 \\
\hline & 25 & 0.0002 & 100.00 & 0.04 & 100.0 \\
\hline
\end{tabular}

Table 3: Inter day and intraday precision of enalapril and NSAIDs.

\begin{tabular}{|c|c|c|c|c|}
\hline & Level & $\mathbf{K}^{\prime}$ & $\mathbf{T}$ & $\left(R_{s}\right)$ \\
\hline \multicolumn{5}{|c|}{ A: $\mathrm{pH}$ of mobile phase } \\
\hline 2.0 & -0.2 & 4.8 & 1.39 & 2.4 \\
\hline 2.5 & 0 & 4.5 & 1.43 & 2.3 \\
\hline 3.0 & 0.2 & 4.2 & 1.4 & 2.2 \\
\hline \multicolumn{2}{|c|}{ Mean \pm S.D $(n=6)$} & $4.5 \pm 0.3$ & $1.43 \pm 0.020$ & $2.3 \pm 0.1$ \\
\hline \multicolumn{5}{|c|}{ B: Flow rate $\left(\mathrm{mLmin}^{-1}\right)$} \\
\hline 0.8 & -0.2 & 4.1 & 1.45 & 2.32 \\
\hline 1 & 0 & 4.2 & 1.45 & 2.36 \\
\hline 1.2 & 0.2 & 4.4 & 1.42 & 2.37 \\
\hline \multicolumn{2}{|c|}{ Mean \pm S.D $(n=6)$} & $4.3 \pm 0.212$ & $1.44 \pm 0.015$ & $2.36 \pm 0.026$ \\
\hline \multicolumn{5}{|c|}{ C: Percentage of water in mobile phase (V/V) } \\
\hline 25 & -5 & 4.6 & 1.42 & 2.38 \\
\hline 20 & 0 & 4.3 & 1.43 & 2.36 \\
\hline 15 & 5 & 4.5 & 1.46 & 2.33 \\
\hline \multicolumn{2}{|c|}{ Mean \pm S.D $(n=6)$} & $4.36 \pm 0.070$ & $2.36 \pm 0.025$ & $2.36 \pm 0.025$ \\
\hline \multicolumn{5}{|c|}{ C: Wavelength $(\mathrm{nm})$} \\
\hline 220 & -5 & 4.5 & 1.42 & 2.38 \\
\hline 225 & 0 & 4.3 & 1.43 & 2.36 \\
\hline 230 & 5 & 4.4 & 1.45 & 2.32 \\
\hline \multicolumn{2}{|c|}{ Mean $\pm S . D(n=6)$} & $4.3 \pm 0.070$ & $1.43 \pm 0.015$ & $2.36 \pm 0.030$ \\
\hline \multicolumn{5}{|c|}{$\begin{array}{c}K^{\prime}=\text { Capacity factors, } N=\text { Theoretical plates, } T=\text { Tailing factor } \\
\text { Rs=Resolution }\end{array}$} \\
\hline
\end{tabular}

Table 4: Robustness of the method.

\section{References}

1. Sweetman SC (2005) Martindale: The Complete Drug Reference. (34thedn) Pharmaceutical Press, London \& Chicago 900-901.

2. Dominic PI, Gerald SB (1987) Analytical Profiles of Drug Substances. Academic Press, New York, pages 207-243.

3. Oates JA (1988) Antagonism of antihypertensive drug therapy by nonsteroidal anti-inflammatory drugs. Hypertension 11: ॥4-6.

4. Mousavy SM (1991) Indomethacin induces hypertensive crisis in preeclampsia irrespective of prior antihypertensive drug therapy. Am J Obstet Gynecol 165: 1577.

5. Sultana N, Arayne MS, Naveed S, Shamshad H (2009) An RP-HPLC method for simultaneous analysis and interaction studies on enalapril maleate and $\mathrm{H}_{2}$ receptor antagonists. Acta Chromatographica 21: 547-558.

6. Yoon KH, Kim W, Park J, Kim HJ (2004) Determination of enalapril in human plasma by high-performance liquid chromatography- electrospray ionization mass spectrometry. Bull Korean Chem Soc 25: 878-880.

7. Ferretti R, Gallinella B, La Torre F, Villani C (1995) Direct high-performance liquid chromatography resolution on chiral columns of tiaprofenic acid and related compounds in bulk powder and pharmaceutical formulations. Journal of Chromatography A 704: 217-223.

8. Niopas I, Mamzoridi K (1994) Determination of indomethacin and mefenamic acid in plasma by high-performance liquid chromatography. J Chromatogr B Biomed Appl 656: 447-450.

9. Stafiej A, Pyrzynska K, Regan F (2007) Determination of anti-inflammatory drugs and estrogens in water by HPLC with UV detection. J Sep Sci 30: 985991.

10. Sultana N, Arayne MS, Tabassum A (2012) Simultaneous quantitation and monitoring of rosuvastatin with NSAIDs by liquid chromatography with UV detection. Research and Reports in Medicinal Chemistry 2: 19-29.

11. Sultana N, Arayne MS, Ali SA (2013) An ultra-sensitive LC method for simultaneous determination of rosuvastatin, alprazolam and diclofenic sodium in API, pharmaceutical formulations and human serum by programming the detector. Journal of Anal and Bioanal Techniques 3: 154

12. Sultana N, Arayne MS, Siddiqui R, Naveed S (2012) RP-HPLC method for the simultaneous determination of lisinopril and NSAIDs in API, pharmaceutical formulations and human serum. American Journal of Analytical Chemistry 3 : 147-152.

13. Sultana N, Arayne MS, Naveed S (2010) Simultaneous quantitation of captopril and NSAIDs in API, dosage formulations and human serum by RP-HPLC. J Chinese Chemical Society 57: 62-67.

14. Arayne MS, Sultana N, Zuberi H, Haroon U (2010) In vitro studies of interaction between metformin and NSAIDs (non steroidal anti-inflamatory drugs) using spectrophotometry and RP-high performance liquid chromatography. J Chi Chem Soc 55: 206-211.

15. Sultana N, Arayne MS, Shafi N, Siddiqui FA (2010) Simultaneous RPLC analysis of diltiazem and non-steroidal anti-inflammatory drugs in pharmaceutical formulations and human serum. Chromatographia 71: 71-77.

16. Sultana N, Arayne MS, Waheed A (2011) Method Development of Verapamil in Presence of NSAIDs using RP-HPLC Technique. Bull Korean Chem Soc 32: $2274-2278$.

17. Sultana N, Arayne MS, Ali SA (2013) An ultra-sensitive LC method for the simultaneous determination of paracetamol, carbamazepine, losartan and ciprofloxacin in bulk drug, pharmaceutical formulation and human serum by programming the detector. AJAC 4: 24-33.

18. Gul S, Sultana N, Arayne MS, Shamim S, Akhtar M (2012) New method for Optimization and simultaneous determination of sparfloxacin andnNon steroidal anti-Inflammatory Drugs: Its In-Vitro Application. American Journal of Analytical Chemistry 328-337.

19. Sultana N, Arayne MS, Naveed S (2011) Simultaneous determination of enalapril and statins in pharmaceutical formulation by RP-HPLC. J Chillean Chemical Society 56: 734-737.

20. Siddiqui FA, Arayne MS, Sultana N, Qureshi F (2011) Developmen and validation of stability-indicating HPLC method for the simultaneous determination of paracetamol, tizanidine, and diclofenac in pharmaceuticals and human serum. J AOAC Int 94: 150-158. 
Citation: Sultana N, Naveed S, Arayne MS (2013) Facile and Manifest Liquid Chromatographic Method for the Simultaneous Determination of Enalpril Maleate and NSAIDs in API and Pharmaceutical Formulations. Pharm Anal Acta S2: 004. doi:10.4172/2153-2435.S2-004

Page 5 of 5

21. Arayne MS, Sultana N, Tabassum A, Ali SN, Safila Naveed S (2012) Simultaneous LC determination of rosuvastatin, lisinopril, captopril and enalapril in API, formulations and human serum by liquid chromatography. Medicinal Chemistry Research.

22. Arayne MS, Sultana N, Zuberi MH, Siddiqui FA (2013) Simultaneous RP-HPLC method for thedDetermination of metformin, captopril, lisinopril and enalapril:
Its applications indDosage formulations and in human plasma. Medicinal Chemistry Research.

23. International Conference on the Harmonization of Technical Requirements for the Registration of Pharmaceuticals for Human Use (ICH) Q2B 1996 Validation of Analytical Procedures, Methodology.
This article was originally published in a special issue, Pharmaceutical Formulations: Regulatory updates handled by Editor(s). Dr. Preveen Hiremath, Pharmaceutics International Inc., USA 